\title{
Noninferiority study evaluating the efficacy of a teat disinfectant containing copper and zinc for prevention of naturally occurring intramammary infections in an automatic milking system
}

\author{
Claudina Vissio, ${ }^{1}$ Armin Mella, ${ }^{2}$ Luis Amestica, ${ }^{3}$ and Martin Pol ${ }^{4 *}$ (]) \\ ${ }^{1}$ Universidad Nacional de Rio Cuarto CONICET, Ruta nacional 36 km 601, Río Cuarto 5800, Córdoba, Argentina \\ ${ }^{2}$ Instituto de Bioquímica y Microbiología, Universidad Austral de Chile, Valdivia 5090000, Chile \\ ${ }^{3}$ R\&D Copper Andino S.A., Santiago de Chile 7501033, Chile \\ ${ }^{4}$ Lactodiagnostico Sur SRL, Olivos 1636, Buenos Aires, Argentina
}

\begin{abstract}
The aim of this study was to demonstrate the noninferiority of a novel teat disinfectant based on copper and zinc (ZkinCu; Copper Andino, Santiago de Chile, Chile) compared with a previously proven glycolic acid active disinfectant (OceanBlu; DeLaval, Kansas City, $\mathrm{MO})$ as a positive control, with respect to the incidence of new intramammary infections under natural challenge conditions on a commercial robotic dairy farm. This study was conducted in 6 robotic pens of approximately 60 milking cows each. The pens were randomly assigned to 1 of the 2 studied disinfectants. Throughout the 8 wk study, the same pre- and postmilking teat disinfectant was used in each pen. The same milking procedures were used in each robot throughout the study. Pre-milking hygiene consisted of applying the disinfectant (OceanBlu or ZkinCu) with the robotic arm. The same product was applied on the teats after milking. At the beginning of the study, all quarters of all study cows were sampled. In successive samplings (wk 2, 4, 6, and 8), composite milk samples were collected on farm to determine SCC. Once composite SCC results were available $(2 \mathrm{~d})$ and based on an SCC of $\geq 100,000$ cells $/ \mathrm{mL}$, quarter milk samples underwent bacteriological culture. Clinical mastitis was identified by study personnel. Intramammary infection in biweekly quarter milk samples was determined based on composite SCC levels $(\geq 100,000$ cells $/ \mathrm{mL})$ and the presence of bacteria. A new IMI was defined as a quarter in which the organism isolated was not present in the previous bacteriological sample, or the previous composite SCC sample was $<100,000$ cells $/ \mathrm{mL}$. Clinical mastitis samples were also considered to be new IMI. The trial was designed as a positive control field
\end{abstract}

Received December 27, 2018.

Accepted July 17, 2019.

*Corresponding author: martin.pol.mastitis@gmail.com trial, in which the objective was to show noninferiority of ZkinCu versus the control (OceanBlu). The overall crude incidences of new IMI for 2 wk at risk were 4.9 and $7.3 \%$ for the ZkinCu and OceanBlu groups, respectively. The predominant organisms recovered from quarters with new IMI were Streptococcus uberis, Corynebacterium spp., and coagulase-negative staphylococci in both the ZkinCu and OceanBlu groups. The risk of infection in the OceanBlu group was higher $(\beta=0.644$; $95 \%$ confidence interval $=0.05-1.22)$. The interaction of treatment by week was not significant. The new IMI rate estimates (95\% confidence interval) for ZkinCu and OceanBlu were $1.7 \%(0.8-2.5)$ and $3.2 \%(1.7-4.7)$, respectively. One novel aspect of this study is that it was one of the first commercial noninferiority trials to evaluate a new pre- and post-milking teat disinfectant in a dairy herd with an automatic milking system. The experimental teat disinfectant ZkinCu, evaluated in this field trial with naturally occurring IMI, showed noninferiority relative to the positive control for the prevention of new IMI. This study was conducted in a herd with an automatic milking system, and the results are applicable to herds with similar characteristics. Additional studies are needed to ensure reproducibility under different management conditions.

Key words: noninferiority trial, teat disinfectant, intramammary infection, automatic milking

\section{INTRODUCTION}

Despite continued advances in prevention and treatment over the past several decades, mastitis in dairy cows remains one of the leading causes of decreased milk production, lower milk quality, animal loss, and ultimately reduced profit for the dairy producer (Ruegg, 2012). Pre- and post-milking disinfection of teats at each milking is a key recommended procedure for preventing new IMI. A teat disinfectant must have several characteristics: germicidal efficacy; able to prevent new IMI; able to maintain teat condition; and leaves no resi- 
dues in milk that can affect human health. Although germicidal activity can be evaluated using in vitro tests (Boddie et al., 2002; Enger et al., 2015), these results cannot be extrapolated to effective mastitis control. Clinical trials evaluate the overall effect of teat disinfection in preventing new IMI (Fitzpatrick et al., 2018).

The product we evaluated in the present study combines copper and zinc salts as active agents. Copper and zinc salts have shown excellent performance as biocides in many applications (Borkow and Gabbay, 2005; Varkey, 2010). As well, these active ingredients contribute to skin health by accelerating the healing process and improving smoothness without percutaneous penetration (Hostynek and Maibach, 2006). Moreover, these elements are already present in milk, and they are essential elements in the human diet (Uauy et al., 1998; Roohani et al., 2013).

Automatic milking is an alternative to conventional milking. Similar to other aspects of the automatic milking process, teat disinfection is performed by the robotic arm. To our knowledge, this is the first field study to evaluate the efficacy of teat disinfection in preventing natural occurring IMI in an automatic milking system. The aim of this study was to demonstrate the noninferiority of a novel teat disinfectant based on copper and zinc (ZkinCu, ZC; Copper Andino, Santiago de Chile, Chile) compared with a previously proven disinfectant based on glycolic acid (OceanBlu, OB; DeLaval, Kansas City, MO) as a positive control with respect to the incidence of new IMI that occurred under natural challenge conditions on a commercial robotic dairy farm.

\section{MATERIALS AND METHODS}

\section{Study Farm and Study Pens}

This noninferiority positive-control field study was conducted on a commercial robotic Holstein dairy farm in Chile. The herd was enrolled in a monthly testing program; herd average milk production, SCC, percent milk fat, and percent protein were $39 \mathrm{~L} / \mathrm{d}, 178,000$ cells $/ \mathrm{mL}, 3.9 \%$, and $3.3 \%$, respectively. Lactating cows are housed in freestall pens with reclaimed deep sand bedding. Alleyways are scraped continually. After calving, cows spend approximately $10 \mathrm{~d}$ in a fresh cow pen being milked in a conventional parlor, after which they are moved into robotic pens. This study was conducted in 6 robotic pens of approximately 60 milking cows each. We observed no differences between treatment groups in relation to SCC, DIM, parity, or milk production (Table 1). The function of the DeLaval Classic robots (DeLaval Manufacturing, Kansas City, MO) was assessed periodically; settings remained according to the manufacturer's recommendations.

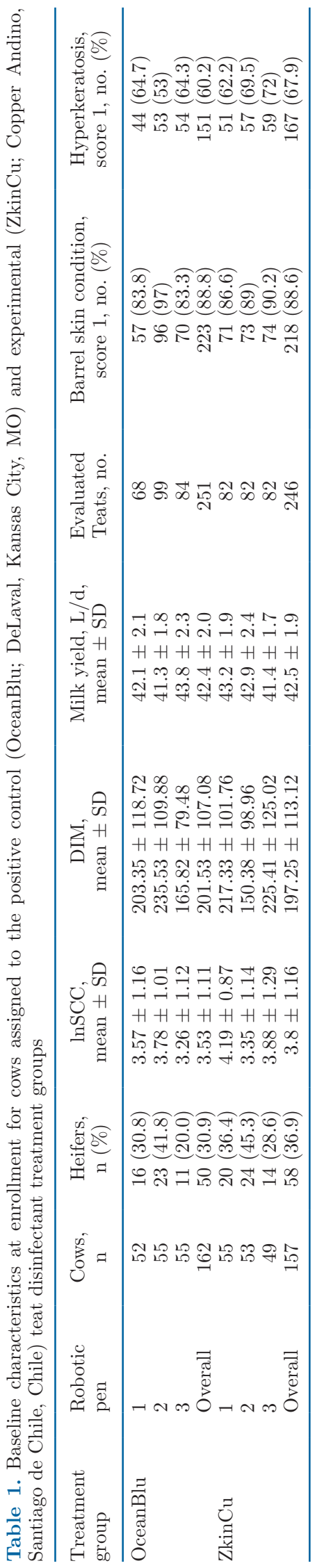




\section{Cow Enrollment}

The pens with OB disinfectant were paired with pens with ZC disinfectant that had the same characteristics for parity and DIM. Cows in a particular pen were exposed to the same disinfectant throughout the study. After the initial treatment group assignment, new cows could be assigned to the study after $10 \mathrm{~d}$ postpartum. Cows diagnosed with clinical mastitis during the study were moved to a hospital pen after being registered. Cows that had clinical mastitis or were lame, dried off, or culled were withdrawn from the study. The studied pens included predominantly older cows, but also some animals in their first lactation.

Two weeks before study initiation, cows were exposed to the studied disinfectants. Application of the disinfectant 2 wk before the beginning of the study was required by the farmer to ensure that the product would not affect spray nozzles or teat skin condition.

\section{Teat Disinfectant Identification}

Throughout the 8-wk study, the same pre- and postmilking teat disinfectant was used on each pen. In this robot model, one disinfectant is used both for dipping before and after milking. Cows in the OB group were treated with OceanBlu Pre-Post (DeLaval, Kansas City, $\mathrm{MO})$, a pre- and post-milking disinfectant that used glycolic acid $(3 \%)$ as the active ingredient, as well as other inactive ingredients in a proprietary blend called GlyTec (DeLaval Manufacturing). In the ZC pens, a novel zinc and copper disinfectant, ZkinCu (Copper Andino, Santiago de Chile, Chile), was used. The active ingredients in the formula were $10,600 \mathrm{mg} / \mathrm{kg}$ zinc ions from a mixture of zinc gluconate $(65 \%$ by wt) and zinc sulfate monohydrate ( $35 \%$ by wt) and $10,600 \mathrm{mg} / \mathrm{kg}$ copper ions from a mixture of copper gluconate (20\% by wt) and copper sulfate pentahydrate ( $80 \%$ by wt). The emollients were $5 \%$ glycerin, $5 \%$ sorbitol, and $1 \%$ propylene glycol. Polyvinyl alcohol was added to achieve a viscosity of $3 \mathrm{cP}$. The balance was demineralized water. The final $\mathrm{pH}$ was 6.1. The products were used from their original containers (60 L barrels) and were clearly marked to avoid misplacements. Study personnel were responsible for marking the barrels, controlling rate of usage, and monitoring blockage of the spray nozzles.

\section{Training and Monitoring}

A resident veterinarian monitored the study and was focused only on this trial. The veterinarian's daily tasks included teat disinfectant coverage, teat condition scoring, and evaluation of animals suspected to have clinical mastitis [high mastitis detection index
(MDi)]. The MDi is based on conductivity, milking interval, and blood detection, and is calculated using DelPro software (DeLaval International AB, Tumba, Sweden). The MDi is calculated at the cow level, not the quarter level, and provides a value on a scale of 1 to 6 that indicates the likelihood of mastitis (Khatun et al., 2018). Cows with a high MDi (>1.4) were evaluated daily (forestrip) by the resident veterinarian for the presence of clinical mastitis. The threshold for visual detection was based on previously suggested optimal thresholds for distinguishing clinical from nonclinical quarters (Khatun et al., 2018).

Before the study began, personnel in charge of test-day sampling were trained in aseptic sampling techniques. We concluded that a 2-person team was needed per robot to perform the sampling of quarters every 2 wk. Clinical mastitis samples were cultured on farm with conventional techniques following National Mastitis Council procedures (Hogan et al., 1999). The study investigator, responsible for cultures, trained the farm laboratory personnel on culturing procedures. The resident veterinarian oversaw activities at sampling events every 2 wk. The study monitor visited the herd at monthly intervals. Tasks performed during visits included evaluation of management and application of the teat disinfectants (disinfectant barrel identification, product application procedures by the robotic arm); measurement and monitoring of product quantities; and reviewing record-keeping and on-farm laboratory procedures.

\section{Application of Teat Disinfectants}

The same milking procedures were used in all cows, and in each robot throughout the study. The teats were cleaned with a cleaning cup, which uses warm water, variable air pressure, and vacuum. Premilking hygiene consisted of applying disinfectant (OB or ZC, depending on the pen) by the robotic arm, spraying in a $\mathrm{W}$ pattern. The same product was applied to teats after milking, using the same pattern.

\section{Milk Sample Collection, SCC Testing and Selection of Quarters for Bacterial Culture}

The study was performed between July 10 and September 11, 2017. At the beginning of the study (wk 0 , baseline sample) and throughout the study period, all quarters of all study cows were sampled. Sampling was performed immediately before milking, using the following technique: after pre-milking disinfection had been performed by the robot, the robotic arm was stopped, the teat end was scrubbed with an alcohol scrub, 3 or 4 squirts of foremilk were discarded onto 
the floor, and then 2 milk samples were collected. Milk samples collected for bacteriological culture were stored at $-20^{\circ} \mathrm{C}$ until shipping.

At wk 2, 4, 6, and 8, composite milk samples were collected on farm for SCC determination using a 13$\mathrm{mL}$ vial containing a bronopol tablet. These samples were processed by the Biosur laboratory the day after the sampling visit, and SCC was determined using flow cytometry. The time lag between sampling and bacteriological culture did not exceed 1 wk.

Once composite SCC results were available, frozen quarter samples from cows with composite SCC $\geq 100,000$ cells $/ \mathrm{mL}$ were shipped for bacterial culture at the Bovine Mastitis Laboratory, Biochemistry and Microbiology Department, Faculty of Sciences, Universidad Austral de Chile (Valdivia, Chile). Staff who performed outcome assessments for SCC and milk bacteriology had no knowledge of treatment assignment.

\section{Teat Condition Scoring}

Teat barrel skin condition and degree of hyperkeratosis were evaluated at wk 0,4 , and 8 in a sample of cows. This evaluation was performed before the udder was prepared by the robot and before the milking unit was attached. Teat barrel skin condition was scored on a scale of 1 to $5(1=$ smooth, supple skin free from scales, cracks, or chapping; $2=$ slight drying of skin with superficial flaking; $3=$ more severe drying with early cracks present; $4=$ more pronounced chapping and cracks in skin, along with redness indicating the presence of inflammation; and $5=$ severe skin damage with deep cracks, open ulcerative lesions, or scabs; Britt and Farnsworth, 1996). Hyperkeratosis of the teat orifice was also scored on a scale of 1 to $5(1=$ smooth teat end and sphincter with no evidence of roughness; $2=$ slight irregularities or fringes of roughness near orifice; 3 = teat end sphincter is moderately roughened with radial cracks; $4=$ teat orifice is significantly roughened with pronounced cracking; and $5=$ teat end is severely roughened with deep irregular callous; Britten et al., 2004).

\section{Microbiological Culture Standard Operating Procedures}

Bacteriological analyses were carried out following accepted standards recommended by the National Mastitis Council (Hogan et al., 1999). A $0.01 \mathrm{~mL}$ aliquot from each milk sample was cultured on blood agar plates (Oxoid Diagnostic Reagents, Basingstoke, UK) containing $5 \%$ sheep blood cells. Plates were incubated at $37^{\circ} \mathrm{C}$ and examined for growth at 24 to $48 \mathrm{~h}$. For plates with bacterial growth, the number of colonies was recorded for each species isolated, and colonies were subcultured on blood agar for further characterization. Colony morphology, hemolysis pattern, and Gram stain results were described for each plate. Further characterization of gram-positive organisms involved catalase test reaction to differentiate between Staphylococcus and Streptococcus species, and followed up with coagulase testing. Organisms that were catalase-positive/coagulase-negative were reported as CNS; catalase-positive/coagulase-positive organisms were reported as Staphylococcus aureus. Catalase-negative organisms had their identity confirmed by SVA Strep (SVA, Uppsala, Sweden). Gram-negative isolates were further tested using the API20 E identification system (bioMérieux SA, Marcy l'Étoile, France), which permits rapid species identification of Enterobacteriaceae and other gram-negative organisms. Yeast was reported separately. If 3 or more different pathogens were present in a sample, it was considered contaminated.

\section{Definitions}

Clinical mastitis was identified using MDi (Khatun et al., 2018) as a screening test. A veterinarian checked cows with an MDi $\geq 1.4$ for the appearance of visibly abnormal milk (watery, flakes, or clots) to confirm the diagnosis. All clinical mastitis events for cows were recorded, and a milk sample was collected from the affected quarter using aseptic technique and frozen for later bacteriological culture.

Intramammary infection in biweekly quarter milk samples was determined using the following IMI definitions from the quarter bacteriological culture result. An IMI was defined as 1 or more colonies isolated from a $0.01 \mathrm{~mL}$ milk sample for all pathogens except CNS and Bacillus spp. For CNS, 2 or more colonies isolated from a $0.01 \mathrm{~mL}$ milk sample were needed to establish presence of an IMI (Dohoo et al., 2011). For Bacillus spp., an IMI was defined as 5 or more colonies isolated from a 0.01-mL milk sample (Arruda et al., 2013). A single IMI was defined as the presence of only 1 type of pathogen in the sample; mixed infections were defined as the presence of 2 different bacterial species. A sample was considered contaminated if 3 or more bacterial species were present. Clinical mastitis samples were also considered an IMI even if culture of the clinical milk sample produced no bacterial growth.

A new IMI was defined as a quarter in which the organism isolated was not present in the previous bacteriological sample or the previous composite SCC sample was $<100,000$ cells $/ \mathrm{mL}$. Clinical mastitis samples were also considered new IMI when supported by bacteriology tests. 


\section{Statistical Analysis}

The primary outcome considered was new IMI. The incidence of new IMI during the study period was calculated as the number of quarters with a new IMI divided by the amount of quarters at risk of a new IMI across all time points. A quarter at risk of a new IMI was defined as a quarter that was not infected or that had previous composite $\mathrm{SCC}<100,000$ cells $/ \mathrm{mL}$. The study hypothesis was that we would find no differences in the incidence of IMI between the control and experimental pre- and post-milking teat dips in reducing naturally occurring infections. We used the difference in the proportion of new IMI and 95\% confidence intervals (CI) to evaluate noninferiority.

The trial was designed as a positive-control field trial, in which the objective was to show noninferiority of the new product (ZC) compared with the existing product used as a control (OB). If the difference between the control and the experimental product is zero or slightly in favor of the control, the products may still be considered equivalent (Schukken et al., 2013). The experimental disinfectant is considered inferior only when the difference is larger than a determined critical value (Schukken et al., 2013; Godden et al., 2016).

This critical value, called margin of noninferiority (d), was selected as the smallest value that would have a clinically important effect. We followed the approach described by Godden et al. (2016) to establish the d-value, using the same assumptions: $70 \%$ efficacy of control product, at least $40 \%$ of efficacy against a negative control of experimental product, and a ratio of less than 2 between the risk of infection with the experimental product and risk of infection with the positive control. The efficacy assumed for $\mathrm{OB}$ was at least $70 \%$ based on previous noninferiority studies (Godden et al., 2016; Lago et al., 2016). We therefore proposed the same noninferiority margin, used by Godden et al. (2016): $d=0.035(3.5 \%)$. We proposed this value based on the incidence of new IMI in a previous study (Hillerton et al., 2007) and because in the present study, the monthly incidence on the farm of new cases of subclinical mastitis using composite SCC from test day at a cut-off of 100,000 cells $/ \mathrm{mL}$ showed values of 2.5 to $4 \%$ in the preceding 3 mo.

Descriptive statistics were generated by treatment group and pen to describe baseline measures at wk 0 , including parity, DIM, $\operatorname{lnSCC}$, the prevalence of IMI $(\%)$, teat barrel skin condition scores, hyperkeratosis scores, and baseline bacteriology results. Descriptive statistics for new IMI by treatment group were generated for exploratory data analysis at the quarter level for each week of analysis $(0,2,4,6$, and 8 wk). We calculated the crude incidence of new IMI as the number of quarters that developed an IMI between successive biweekly sampling events divided by the number of quarters at risk for new IMI during that 2-wk interval. We calculated the crude prevalence of IMI during the study period as the number of IMI at a given time point divided by the number of quarters sampled at that time point.

The quarter was the unit of interest. The effect of treatment on quarter-level risk for new IMI for each 2-wk sampling interval was modeled as a function of treatment group and other covariates using mixed logistic regression. The final mixed model was as follows:

$$
\begin{gathered}
f\left(Y_{i j k}\right)=\text { intcpt }+\beta_{1} \times \text { treatment }+\beta_{k} \times \text { covariates }_{k} \\
+ \text { week }^{+} \text {treatment } \times \text { week }+ \text { cow }_{j}(\text { random }) \\
+ \text { quarter }_{i}\left(\text { cow }_{j}\right)(\text { random })+\text { error }_{i j k},
\end{gathered}
$$

where $f(Y)$ was the logit link function; $Y_{i j k}$ was the occurrence of a new IMI (yes/no) in the quarter $;$; intcpt was the intercept; treatment was the variable indicating whether a quarter was in the $\mathrm{ZC}$ or $\mathrm{OB}$ group; and $\beta_{1}$ referred to the regression coefficient for treatment. Other covariates $\left(\beta_{k}\right)$ investigated included quarter location $(\mathrm{A}=$ right front, $\mathrm{B}=$ left front, $\mathrm{C}=$ right hind, $\mathrm{D}=$ left hind), lactation, and DIM. Time of sample collection (wk 2, 4, 6, or 8) was forced as a fixed effect into the model. Cow was an indicator for $c_{0} w_{j}$ that we used as a random effect to model the within-cow correlation of quarters in the same cow. Quarter ${ }_{i}\left(\operatorname{cow}_{j}\right)$ was used as a random effect to model the longitudinal correlation of observations within the same quarter. Error refers to the residual term in the model. An independent correlation structure as used in all models.

Teat condition was compared using general linear mixed models to determine any difference by treatment and time. The teat condition score for barrel skin and hyperkeratosis were the response variables and time of teat evaluation (wk 0,4, or 8) and treatment group were used as fixed effect in the model. Cow was used as a random effect to model the within-cow correlation of quarters in the same cow. Analyses were carried out using STATA (version 11; StataCorp, College Station, TX). The noninferiority analysis of the effect of treatment with ZC on risk of new IMI was completed by calculating the new IMI proportion difference $(95 \% \mathrm{CI})$ for ZC compared with $\mathrm{OB}$, and then comparing the upper bound of the CI for the rate difference for ZC against the critical value.

\section{RESULTS AND DISCUSSION}

A total of 319 cows from 6 pens were enrolled in the study on July 10, and 157 and 162 cows were assigned 
to the ZC and OB groups, respectively. The numbers of cows that finished the trial at wk 8 were 117 and 120 in the ZC and OB group, respectively; 30 and 23 cows were added to the $\mathrm{ZC}$ and $\mathrm{OB}$ pens, respectively.

Each pen included an average of 53.2 milking cows [standard deviation $(\mathrm{SD})=2.4$ ]. The pen average of DIM varied between 150.4 and $235.5 \mathrm{~d}$, and the pen proportion of heifers varied between 20 and $46 \%$. The mean (SD; range) parity and DIM for all cows at wk 0 were 2.03 lactations $(0.95 ; 1-5)$ and $199.42 \mathrm{~d}$ (109.94; 39-662), respectively; we found no difference between the $\mathrm{ZC}$ and $\mathrm{OB}$ groups. The mean (SD; range) of $\operatorname{lnSCC}$ and the prevalence of IMI for all quarters at wk 0 were $3.15(1.42 ; 0-9.06)$ and $18.7 \%$, respectively; we found no difference between the $\mathrm{ZC}$ and $\mathrm{OB}$ groups (Table 1). Minor pathogens (Corynebacterium spp. and CNS) were the most prevalent in both $\mathrm{ZC}$ and $\mathrm{OB}$ group (Table 2). A total of 701 and 675 teat skin condition evaluations were performed at wk 0,4 , and 8 in the $\mathrm{ZC}$ and $\mathrm{OB}$ groups, respectively. The proportion of teats with normal teat barrel skin and hyperkeratosis degree $($ score $=1$ ) was similar for the $\mathrm{ZC}$ and $\mathrm{OB}$ groups at the beginning of study (Table 1).

In this study, the farm design and robot model did not allow us to randomly assign cows to each treatment group. As a result, assignment to treatment was paired, showing similar baseline characteristics between treatment groups and indicating that the differences between groups could be related to treatment. The disinfectant stayed the same in each robotic pen, and cows remained in the same robotic pen at every time point throughout the study. In addition, the robot used in the study applied the same disinfectant pre- and post-

Table 2. Baseline bacteriology results at enrollment (wk 0) for quarters assigned to the positive control (OceanBlu; DeLaval, Kansas City, MO) and experimental (ZkinCu; Copper Andino, Santiago de Chile, Chile) teat disinfectant treatment groups

\begin{tabular}{lcc}
\hline & \multicolumn{2}{c}{ Treatment group, no. (\%) } \\
\cline { 2 - 3 } Bacteriology results & ZkinCu & OceanBlu \\
\hline Samples cultured & $609(100)$ & $617(100)$ \\
Contaminated & $4(0.7)$ & $15(2.4)$ \\
Negative & $495(81.3)$ & $502(81.4)$ \\
Samples with growth & $110(18.1)$ & $100(16.2)$ \\
Bacillus spp. & $3(0.5)$ & $3(0.5)$ \\
Coliform & $1(0.2)$ & $3(0.5)$ \\
Corynebacterium spp. & $18(3)$ & $17(2.8)$ \\
Yeast & $2(0.3)$ & - \\
Pseudomonas spp. & $1(0.2)$ & - \\
CNS & $68(11.2)$ & $68(11)$ \\
CNS-Corynebacterium spp. & $3(0.5)$ & - \\
Staphylococcus aureus & $3(0.5)$ & $1(0.2)$ \\
Streptococcus dysgalactiae & $4(0.7)$ & $2(0.3)$ \\
Streptococcus uberis & $7(1.1)$ & $6(1)$ \\
\hline
\end{tabular}

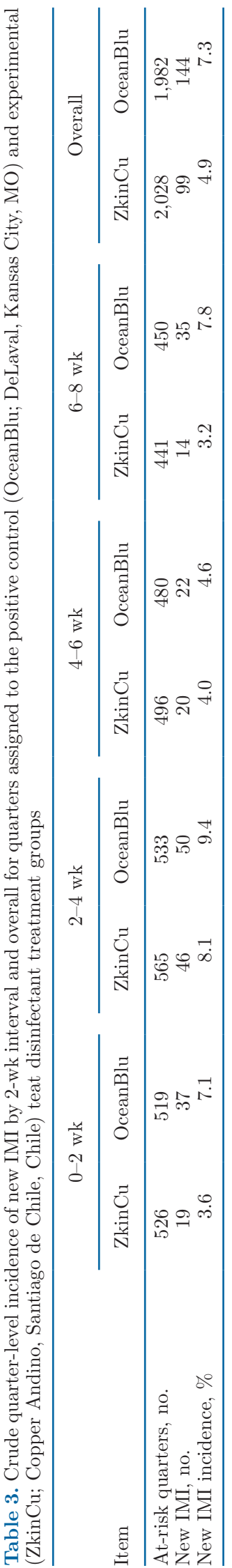


Table 4. Etiology of new IMI acquired during the 8-wk study for quarters assigned to the positive control (OceanBlu; DeLaval, Kansas City, MO) and experimental (ZkinCu; Copper Andino, Santiago de Chile, Chile) teat disinfectant treatment groups

\begin{tabular}{lcc}
\hline & \multicolumn{2}{c}{ Treatment group, no. (\%) } \\
\cline { 2 - 3 } Item & ZkinCu & OceanBlu \\
\hline Quarters at risk of new IMI & 2,028 & 1,982 \\
Quarters with new IMI & $99(4.9)$ & $144(7.3)$ \\
Streptococcus uberis & $7(7.1)$ & $15(10.4)$ \\
Corynebacterium spp. & $24(24.2)$ & $20(13.9)$ \\
Streptococcus dysgalactiae & $1(1)$ & $1(0.7)$ \\
CNS & $26(26.3)$ & $51(35.4)$ \\
Clinical mastitis without bacterial growth & $27(27.3)$ & $37(25.7)$ \\
BnoF ${ }^{1}$ & $5(5.1)$ & $4(2.8)$ \\
Yeast & $2(2)$ & $8(5.6)$ \\
Pseudomonas spp. & $1(1)$ & - \\
CNS-Corynebacterium spp. & $1(1)$ & - \\
Streptococcus uberis-Corynebacterium spp. & $4(4)$ & - \\
Staphylococcus aureus & $1(1)$ & $1(0.7)$ \\
Bacillus spp. & - & $2(1.4)$ \\
Coliforms & - & $2(1.4)$ \\
Streptococcus agalactiae & - & $2(1.4)$ \\
Streptococcus uberis-CNS & - & $1(0.7)$ \\
\hline BnoF &
\end{tabular}

${ }^{1} \mathrm{BnoF}=$ gram-negative and nonfermentative rods.

milking, so it was not possible to assess effectiveness separately.

The overall crude incidence of new IMI for a 2 -wk period at risk was 4.9 and $7.3 \%$ for the $\mathrm{ZC}$ and $\mathrm{OB}$ groups, respectively (Table 3 ). The predominant organisms recovered from quarters with new IMI were Streptococcus uberis, Corynebacterium spp., and CNS in both the ZC and the OB groups (Table 4). The similar frequency of organisms isolated as the cause of new IMI in both treatment groups was expected, because all cows in the study herd were managed in the same way. The low frequency of major pathogens such as Staphylococcus aureus could be because the herd was relatively well managed in relation to udder health.

In the final mixed logistic regression model, only the variable treatment was significant; quarter location, DIM, and parity were not significant. The risk of infec- tion in the OB group was higher $(\beta=0.644 ; 95 \% \mathrm{CI}$ : $0.05-1.22 ; P=0.03)$. The interaction of treatment by week was not significant. Although week of sampling had no effect on risk for new IMI, we did force this variable into the model. This lack of association may have been because no seasonal changes occurred during the study period. In relation to parity and quarter location, Godden et al. (2016) reported similar results in a trial with similar characteristics. The risk of IMI is greater at peak lactation (Zadoks et al., 2001; Olde Riekerink et al., 2007). In this study, few cows were evaluated at peak lactation, and this could explain the lack of association between DIM and new IMI.

The new IMI rate estimates $(95 \% \mathrm{CI})$ for $\mathrm{ZC}$ and OB were $1.7 \%(0.8-2.5)$ and $3.2 \%(1.7-4.7)$, respectively. The claim of noninferiority was made because the right-hand side of the $95 \%$ CI of the rate difference was smaller than the predefined noninferiority limit of $\mathrm{d}$, defined a priori as $3.5 \%$ (or 0.035 ). The new IMI differences $(95 \% \mathrm{CI})$ for $\mathrm{ZC}$ were $-1.5 \%$ ( -3.2 to -0.2$)$, because the upper bound of the CI for the rate difference was to the left of the critical value d (3.5\%), so we can conclude that $\mathrm{ZC}$ was noninferior relative to $\mathrm{OB}$ with respect to risk for new IMI (Figure 1).

Initial teat barrel skin scores were not different for the $\mathrm{ZC}$ and $\mathrm{OB}$ treatment groups, did not change with time for either group, and were never significantly different (Table 5). Hyperkeratosis scores were significantly different between wk 0 and other weeks $(P<0.05)$, but we found no significant differences between $\mathrm{ZC}$ and $\mathrm{OB}$ for each week evaluated (Table 5).

One novel aspect of this study is that it was one of the first commercial noninferiority trials conducted to evaluate a new teat disinfectant in a dairy herd with an automatic milking system. We obtained these results using a 2-step diagnostic process: at each sample point, all composite milk samples were tested for SCC (screening test) and, on average, $26 \%$ of those cows were also tested using microbiological culture at the quarter level. The first step is screening at the cow level

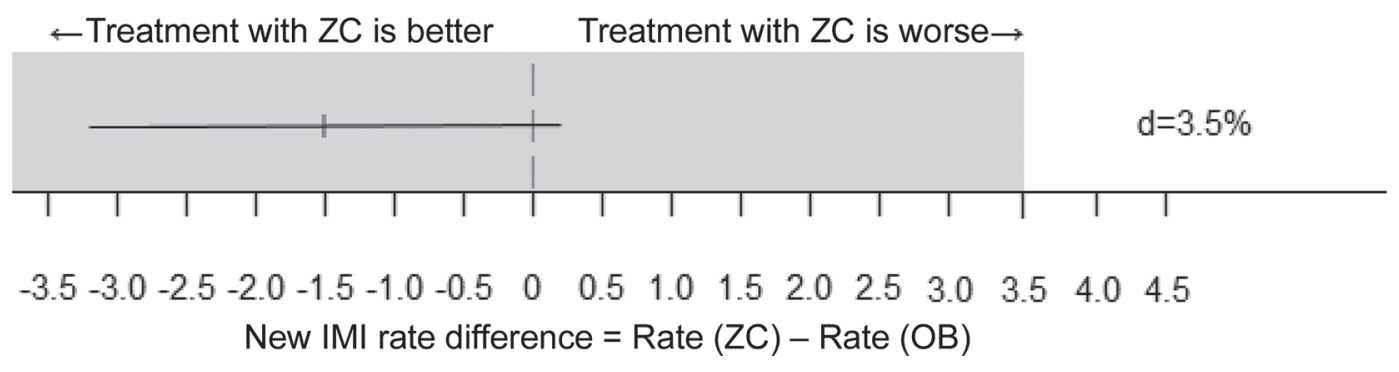

Figure 1. Difference in new IMI rates between the ZkinCu (ZC; Copper Andino, Santiago de Chile, Chile) dip and the OceanBlu (OB; DeLaval, Kansas City, MO) dip in the noninferiority trial. The gray area indicates the zone of noninferiority. $\mathrm{d}=\Delta$, the critical value for declaring inferiority. 
to select animals with at least one quarter that may be infected. The SCC is a valuable screening tool, because it is quick and inexpensive. We used a cut-off of 100,000 cells/mL, considering previous reports of composite SCC sensitivity (Vissio et al., 2014). High sensitivity values $(85 \%)$ in low-prevalence situations (such as this herd) increase the negative predictive value of negative results and reduce the chance of false negatives. The second step was the determination of infection at the quarter level. Serial testing, as used in this study, maximizes the specificity and predictive value of a positive test result, but lowers sensitivity and negative predictive value (Thrusfield, 2007). In this study, with a low incidence scenario, a strategy to optimize specificity would generally be recommended (Smith and Slenning, 2000). A similar approach was used to evaluate premilking teat disinfectant efficacy based on quarter SCC to screen, and the introduced bias due to diagnostic error was relatively small (Ceballos-Marquez et al., 2013). In the present study, the dilution effect of milk on SCC using composite samples could affect the sensitivity to detect IMI; to compensate for this lack of sensitivity, we used a low SCC threshold (100,000 cells $/ \mathrm{mL})$ for all cows. In this sense, when the threshold changes from 200,000 to 100,000 cells $/ \mathrm{mL}$, the sensitivity increases by approximately $15 \%$ (Vissio et al., 2014).

A limitation of this study was our inability to evaluate the novel product (ZC) as post-milking teat disinfection only, because the robot applied the same disinfectant pre- and post-milking; this means that the results are not strictly comparable with the efficacy reported in other studies. In addition, the positive control efficacy used in the present study was reported only for post-milking teat disinfection and not for pre and post-milking. Further studies are needed, using different robot settings, to evaluate the disinfectant efficacy as a post-dip alone.

Another issue to consider was the application of the disinfectant 2 weeks before the beginning of our study. This practice was not reported previously in other trials. In a similar study, cows were assigned to treatment after calving (Godden et al., 2016). Similarly, in the present study, cows that were enrolled after calving did not experience previous exposure to the products. On the other hand, the products were used for a short period of previous exposure (2 weeks) and had no therapeutic action. Therefore, the infection rate in the 2 weeks before the beginning of the trial should not have been affected.

The present study was focused strictly on the evaluation of ZC efficacy on the rate of IMI; because of this, it was not possible to evaluate the effect of $\mathrm{ZC}$ on robot structure and functionality. Further studies of longer duration and suitable design are needed to evaluate

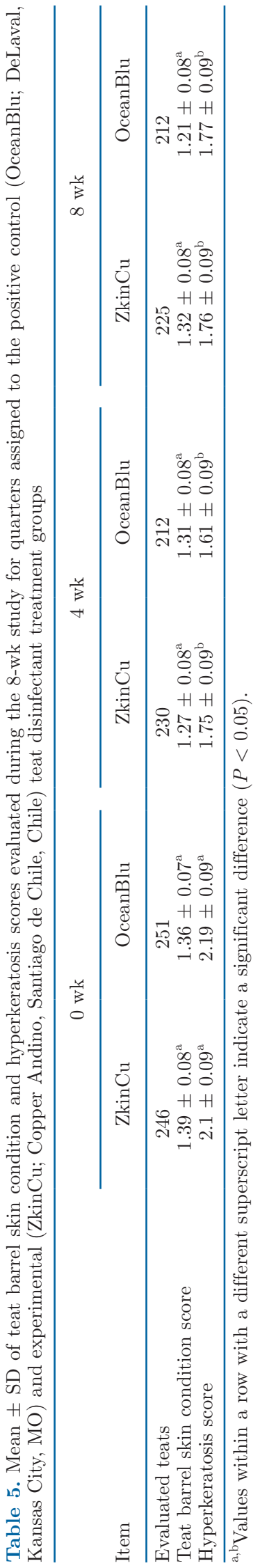


issues such as corrosion, mineral deposit, soil, nozzle capping, and others.

\section{CONCLUSIONS}

The experimental teat disinfectant ZkinCu (Copper Andino), evaluated in this field trial with naturally occurring IMI, showed noninferiority relative to the positive control for the prevention of new IMI. This study was conducted in a herd with an automatic milking system, and the results are applicable to herds with similar characteristics. Additional studies are needed to ensure reproducibility under different management conditions.

\section{ACKNOWLEDGMENTS}

The authors thank farm personnel and veterinarian Pamela Molina for their help in the different tasks needed to carry out this study. Financial support for this study was provided by Copper Andino SA (Santiago de Chile, Chile).

\section{REFERENCES}

Arruda, A. G., S. Godden, P. Rapnicki, P. Gorden, L. Timms, S. S. Aly, T. W. Lehenbauer, and J. Champagne. 2013. Randomized noninferiority clinical trial evaluating 3 commercial dry cow mastitis preparations: I. Quarter-level outcomes. J. Dairy Sci. 96:44194435. https://doi.org/10.3168/jds.2012-6461.

Boddie, R. L., W. E. Owens, C. H. Ray, S. C. Nickerson, and N. T. Boddie. 2002. Germicidal activities of representatives of five different teat dip classes against three bovine mycoplasma species using a modified excised teat model. J. Dairy Sci. 85:1909-1912. https:/ /doi.org/10.3168/jds.S0022-0302(02)74266-5.

Borkow, G., and J. Gabbay. 2005. Copper as a biocidal tool. Curr. Med. Chem. 12:2163-2175. https://doi.org/10.2174/0929867054637617.

Britt, J., and R. Farnsworth. 1996. Here's a system for evaluating teat condition. Pages 570-571 in Hoard's Dairyman.

Britten, A., N. Hanson, and J. Pedraza. 2004. Effect of teat dips on hyperkeratosis. Pages 286-287 in Proc. Natl. Mastitis Counc. 43rd Annu. Mtg. Charlotte, NC. National Mastitis Council, Madison, WI.

Ceballos-Marquez, A., T. Hemling, B. J. Rauch, M. Lopez-Benavides, and Y. H. Schukken. 2013. Noninferiority trial on the efficacy of premilking teat disinfectant against naturally occurring new intramammary infections using a novel 2-step diagnostic process. J. Dairy Sci. 96:8081-8092. https://doi.org/10.3168/jds.2013-7108.

Dohoo, I. R., J. Smith, S. Andersen, D. F. Kelton, and S. Godden. 2011. Diagnosing intramammary infections: Evaluation of definitions based on a single milk sample. J. Dairy Sci. 94:250-261. https://doi.org/10.3168/jds.2010-3559.

Enger, B. D., L. K. Fox, J. M. Gay, and K. A. Johnson. 2015. Reduction of teat skin mastitis pathogen loads: Differences between strains, dips, and contact times. J. Dairy Sci. 98:1354-1361. https: //doi.org/10.3168/jds.2014-8622.

Fitzpatrick, S., M. Garvey, and D. Gleeson. 2018. A review of test protocols for the evaluation of teat disinfectants. Int. J. Dairy Technol. 71:553-563. https://doi.org/10.1111/1471-0307.12516.
Godden, S. M., E. Royster, W. Knauer, J. Sorg, M. Lopez-Benavides, Y. Schukken, S. Leibowitz, and E. A. French. 2016. Randomized noninferiority study evaluating the efficacy of a postmilking teat disinfectant for the prevention of naturally occurring intramammary infections. J. Dairy Sci. 99:3675-3687. https://doi.org/10 .3168/jds.2015-10379.

Hillerton, J. E., J. Cooper, and J. Morelli. 2007. Preventing bovine mastitis by a postmilking teat disinfectant containing acidified sodium chlorite. J. Dairy Sci. 90:1201-1208. https://doi.org/10 .3168/jds.S0022-0302(07)71607-7.

Hogan, J. S., R. N. Gonzalez, R. J. Harmon, S. C. Nickerson, S. P. Oliver, J. W. Pankey, and K. L. Smith. 1999. Laboratory Handbook on Bovine Mastitis. Rev. ed. NMC Inc., Madison, WI.

Hostynek, J. J., and H. I. Maibach. 2006. Copper and the Skin. Informa, New York, NY.

Khatun, M., P. C. Thomson, K. L. Kerrisk, N. A. Lyons, C. E. F. Clark, J. Molfino, and S. C. García. 2018. Development of a new clinical mastitis detection method for automatic milking systems. J. Dairy Sci. 101:9385-9395. https://doi.org/10.3168/jds.2017 -14310 .

Lago, A., D. R. Bruno, M. Lopez-Benavides, and S. Leibowitz. 2016. Short communication: Efficacy of glycolic acid-based and iodinebased postmilking barrier teat disinfectants for prevention of new intramammary infections in dairy cattle. J. Dairy Sci. 99:74677472. https://doi.org/10.3168/jds.2015-10666.

Olde Riekerink, R. G. M., H. W. Barkema, and H. Stryhn. 2007. The effect of season on somatic cell count and the incidence of clinical mastitis. J. Dairy Sci. 90:1704-1715. https://doi.org/10.3168/jds .2006-567.

Roohani, N., R. Hurrell, and R. S. R. Kelishadi. 2013. Zinc and its importance for human health. J. Res. Med. Sci. 18:144-157.

Ruegg, P. L. 2012. Mastitis in dairy cows. Vet. Clin. North Am. Food Anim. Pract. 28:xi-xii. https://doi.org/10.1016/j.cvfa.2012.04.003.

Schukken, Y. H., B. J. Rauch, and J. Morelli. 2013. Defining standardized protocols for determining the efficacy of a postmilking teat disinfectant following experimental exposure of teats to mastitis pathogens. J. Dairy Sci. 96:2694-2704. https://doi.org/10.3168/ jds.2012-6222.

Smith, R. D., and B. D. Slenning. 2000. Decision analysis: Dealing with uncertainty in diagnostic testing. Prev. Vet. Med. 45:139-162. https://doi.org/10.1016/S0167-5877(00)00121-5.

Thrusfield, M. 2007. Veterinary Epidemiology. 3rd ed. Blackwell Science, Hoboken, NJ.

Uauy, R., M. Olivares, and M. Gonzalez. 1998. Essentiality of copper in humans. Am. J. Clin. Nutr. 67:952S-959S.

Varkey, A. J. 2010. Antibacterial properties of some metals and alloys in combating coliforms in contaminated water. Sci. Res. Essays 5:3834-3839.

Vissio, C., S. A. Dieser, H. L. Agnelli, L. M. Odierno, and A. J. Larriestra. 2014. Accuracy of the composite somatic cell count to detect intra-mammary infection in dairy cows using latent class analysis. Prev. Vet. Med. 113:547-555. https://doi.org/10.1016/j.prevetmed .2013.11.016.

Zadoks, R. N., H. G. Allore, H. W. Barkema, O. C. Sampimon, G. J. Wellenberg, Y. T. Gröhn, and Y. H. Schukkent. 2001. Cow- and quarter-level risk factors for Streptococcus uberis and Staphylococcus aureus mastitis. J. Dairy Sci. 84:2649-2663. https://doi .org/10.3168/jds.S0022-0302(01)74719-4.

\section{ORCIDS}

Martin Pol ๑ https://orcid.org/0000-0002-8276-800X 